\title{
ÓLEO ESSENCIAL DE Aloysia citriodora NO CONTROLE DE Sclerotinia sclerotiorum EM PEPINO E ATIVIDADE ANTIFÚNGICA IN VITRO
}

\author{
Álvaro Rodrigo Freddo ${ }^{*}$, Adriano Lewandowski ${ }^{2}$, Cleverson Busso ${ }^{3}$, Flávio Endrigo \\ Cechim $^{1}$, Ivan Carlos Zorzzi ${ }^{2}$, Maristela dos Santos Rey ${ }^{3}$, Nean Locatelli Dalacosta ${ }^{2}$, Sérgio \\ Miguel Mazaro ${ }^{3}$ \\ ${ }^{1}$ Doutorando, Programa de Pós-Graduação em Agronomia, Universidade Tecnológica Federal do Paraná - \\ UTFPR, Campus Pato Branco, PR. *Autor para correspondência. E-mail: a.r.freddo@bol.com.br. \\ ${ }^{2}$ Graduando em Engenharia Agronômica, Universidade Tecnológica Federal do Paraná - UTFPR, Campus \\ Dois Vizinhos, PR. \\ ${ }^{3} \operatorname{Prof(a).~Dr(a).,~Universidade~Tecnológica~Federal~do~Paraná~-~UTFPR,~Campus~Dois~Vizinhos,~PR.~}$
}

RESUMO: O presente trabalho teve como objetivo principal avaliar o potencial do óleo essencial de erva-luísa (Aloysia citriodora) no tratamento de sementes de pepino, para controle de tombamentos de plântulas causados por Sclerotinia sclerotiorum e atividade antifúngica in vitro. Foram realizados dois experimentos in vitro e um teste in vivo com o tratamento das sementes com o óleo essencial. No primeiro experimento, avaliou-se atividade antifúngica in vitro de concentrações do óleo essencial em meio BDA, no crescimento micelial de $S$. sclerotiorum, em placas de Petri. No segundo experimento in vitro, avaliou-se o efeito do óleo essencial em concentrações em meio de cultura BDA, na germinação miceliogênica de escleródios. No terceiro experimento, testou-se o tratamento das sementes em óleo essencial de A. citriodora diluído em água destilada mais espalhante adesivo Tween 80. As sementes foram semeadas em substrato inoculado com $S$. sclerotiorum. Avaliou-se neste experimento: porcentagem de emergência; tombamento de plântulas de pós-emergência; massa verde média por plântula; altura média de plântulas; e análises bioquímicas (teor de proteínas; atividade enzimática de peroxidases; fenilalanina amônia-liase (FAL); $\beta$-1.3-glucanases e quitinases). Os resultados obtidos demonstraram que o óleo tem potencial fungistático e fungicida in vitro sendo a maior redução observada nas maiores doses testadas e também no controle do tombamento de plântulas, onde observou-se melhor resultado na concentração de $0,06 \%$. Além disso, o óleo essencial de $A$. citriodora aplicado às sementes, induziu mecanismos bioquímicos de resistência, evidenciados pelo aumento da atividade bioquímica das peroxidases até a concentração de $0,24 \%$ e da FAL e $\beta-1.3$-glucanases em todas as concentrações testadas.

Palavras-chave: Controle alternativo. Plantas medicinais. Fitopatologia. Mofo branco. Cucumus sativus $\mathrm{L}$.

\section{ESSENTIAL OIL OF Aloysia citriodora IN CONTROL OF Sclerotinia sclerotiorum ON CUCUMBER AND ANTIFUNGAL ACTIVITY IN VITRO}

\begin{abstract}
This study aimed to evaluate the potential of the essential oil of fennel luísa (Aloysia citriodora) in the treatment of cucumber seeds to control damping off caused by
\end{abstract}

Cultura Agronômica, Ilha Solteira, v.25, n.4, p.373-386, 2016 
Sclerotinia sclerotiorum and its antifungal activity in vitro. There were two in vitro experiments and one in vivo with seed treatment with the essential oil. In the first experiment it was evaluated the antifungal in vitro acitivity of concentrations of essential oil on PDA, about mycelial growth of S. sclerotiorum, in Petri dishes. The second in vitro experiment itwas evaluated the effect of the essential oil at concentrations in PDA culture medium, in sclerotia miceliogenic germination. In the third experiment it was tested seed treatment with essential oil from A. citriodora diluted in distilled water plus Tween 80 adhesive spreader. The seeds were sown in substrate inoculated with $S$. sclerotiorum. It was evaluated in this experiment: emergency percentage; post emergence damping off; medium green mass per plant; average height of seedlings; and biochemistry (protein content, enzymatic activity of peroxidases; phenylalanine ammonia lyase (PAL); $\beta$-1,3-glucanases and chitinases). The results showed that the oil has fungistatic and fungicidal potential in vitro being the largest reduction observed in the highest doses tested and also in the control of damping off, where it was observed a better result in the concentration of $0.06 \%$. In addition, the essential oil of $A$. citriodora applied to the seeds induced resistance biochemical mechanisms, evidenced by the increase of the biochemical activity of the peroxidases to the concentration of $0.24 \%$ and of the FAL and $\beta-1,3$-glucanases in all concentrations tested.

Key words: Alternative control. Medicinal herbs. Phytopatology. White mold. Cucumus sativus L.

\section{INTRODUÇÃO}

O pepino é muito cultivado em ambiente protegido e uma das principais doenças neste sistema é o mofo branco, causado por Sclerotinia sclerotiorum (Lib.) de Bary (ETHUR et al., 2005). O patógeno produz estruturas de resistência, denominadas de escleródios, podendo persistir por vários anos no solo (BEDENDO, 2011), o que dificulta o seu controle, podendo inviabilizar e até mesmo causar o abandono da atividade na estufa (VIDA et al., 2004). Os escleródios ao germinarem de forma miceliogênica podem causar tombamentos em pré e pós-emergência em plântulas de pepino (ETHUR et al., 2005).

O controle químico de sementes e do solo são as principais medidas utilizadas para controlar este tipo de patógeno. No entanto, Schwan-Estrada (2009) relata que o uso intensivo e indiscriminado de agroquímicos, ocasiona diversos problemas ambientais, relacionados à contaminações diversas; intoxicação de trabalhadores rurais; eliminação de organismos benéficos e o surgimento de resistência de patógenos a seus ingredientes ativos.

As plantas medicinais podem ser exploradas na obtenção de pesticidas naturais, pelo uso de seus extratos brutos e/ou óleos essenciais (MORAIS, 2009), cujo potencial no controle de fitopatógenos, pode ocorrer tanto por sua ação fungitóxica direta, quanto pela indução de componentes de defesa vegetal, evidenciando seu caráter muitas vezes elicitor (SCHWAN-ESTRADA et al., 2000). Smith (1996) relata que elicitores são moléculas de 
qualquer origem, quer seja biótica ou abiótica, capazes de estimular respostas de defesa nas plantas.

Trabalhos in vitro relatam o potencial antifúngico de erva-luísa (Aloysia citriodora Palau) (DUARTE et al., 2005; ALI et al., 2011; LÓPEZ et al., 2004; COMBRINCK et al., 2011; LOZADA et al., 2012; BOUCHRA et al., 2003), entretanto, são escassos ou inexistentes, os que relatam sua atividade antifúngica a $S$. sclerotiorum, bem como sua aplicação prática no controle a campo. Este trabalho teve como objetivo avaliar o efeito do óleo essencial de A. citriodora no controle dos tombamentos de plântulas de pepino causados por $S$. sclerotiorum e evidenciar se o efeito advém da atividade antifúngica/fungistática direta ou por indução de mecanismos bioquímicos de resistência.

\section{MATERIAL E MÉTODOS}

\section{Experimentos in vitro}

O óleo essencial das plantas de A. citriodora foi extraído em maio de 2014, coletando as plantas nas primeiras horas do período da manhã. A extração foi feita em aparelho de hidrodestilação, modelo Clevenger. O isolado utilizado foi obtido a partir de escleródios de S. sclerotiorum, os quais foram transferidos para meio BDA (batata dextrose ágar). A incubação foi feita em câmara de crescimento a $24^{\circ} \mathrm{C} \pm 1{ }^{\circ} \mathrm{C}$, com fotoperíodo de 12 horas, repicando-se o micélio até a obtenção de colônias puras do fungo.

$\mathrm{O}$ primeiro experimento in vitro consistiu em avaliar o crescimento radial em $\mathrm{cm}$ do patógeno em placas de Petri, contendo concentrações de óleo essencial de A. citriodora em meio BDA $(0,01 \% ; 0,03 \% ; 0,06 \% ; 0,12 \% ; 0,25 \%$ e $0,50 \%)$ mais a testemunha (meio BDA puro). Utilizou-se delineamento inteiramente ao acaso, com quatro repetições por tratamento, sendo considerada como repetição, cada placa de Petri utilizada $(8 \mathrm{~cm} \phi)$.

$\mathrm{O}$ meio de cultura BDA utilizado no experimento foi esterilizado em autoclave, a temperatura de $120{ }^{\circ} \mathrm{C}$, por vinte minutos. O óleo essencial foi incorporado, após o resfriamento (temperatura em torno de $40{ }^{\circ} \mathrm{C}$ ) do meio de cultura. O patógeno foi manipulado em câmara de fluxo laminar, sendo colocado no centro de cada placa, na forma de disco de micélio puro, com o diâmetro de $7 \mathrm{~mm}$. Após as unidades experimentais foram fechadas e acondicionadas em câmara de crescimento, na temperatura de $24{ }^{\circ} \mathrm{C} \pm 1{ }^{\circ} \mathrm{C}$ e fotoperíodo de doze horas. $\mathrm{O}$ experimento foi encerrado quando a primeira placa foi atingida nas bordas pelo crescimento radial do fungo ( 72 horas de crescimento).

No segundo experimento in vitro, avaliou-se o índice de velocidade de germinação miceliogênica de escleródios de $S$. sclerotiorum, em função de concentrações $(0,01 \%$; $0,03 \% ; 0,06 \% ; 0,12 \% ; 0,25 \%)$ de óleo essencial de A. citriodora em meio BDA, mais a testemunha (BDA puro),. em delineamento inteiramente casualizado com cinco repetições, sendo considerada como repetição uma placa de Petri $(8 \mathrm{~cm} \phi)$, contendo dez escleródios por placa. As placas foram tampadas e acondicionadas em câmara de crescimento, com temperatura de $24{ }^{\circ} \mathrm{C} \pm 1{ }^{\circ} \mathrm{C}$ e fotoperíodo de 12 horas, por oito dias.

Cultura Agronômica, Ilha Solteira, v.25, n.4, p.373-386, 2016 


\section{Experimento in vivo}

No terceiro experimento, avaliou-se o efeito do tratamento das sementes de pepino com concentrações de óleo essencial de A. citriodora (0,06\%; 0,12\% e 0,25\%), em água destilada mais espalhante adesivo Tween $80(0,5 \%)$ e a testemunha em água destilada mais espalhante adesivo Tween 80 (0,5\%), em delineamento inteiramente ao acaso, com cinco repetições. Cada unidade experimental consistiu de bandejas de isopor, com cem células de $0,03 \mathrm{~cm}^{3}$ cada. As células receberam substrato inoculado com micélio de S. sclerotiorum produzido em grãos de trigo autoclavados.

O substrato utilizado no experimento foi da marca Tecnomax ${ }^{\circledR}$ para horticultura, sendo previamente desinfestado em autoclave por quarenta minutos a $120^{\circ} \mathrm{C}$. Após a desinfecção, os grãos de trigo miceliados com o inóculo, foram misturados ao substrato, na quantidade de $20 \mathrm{~g} \mathrm{Kg}^{-1}$, o qual foi colocado nas bandejas de isopor, dez dias antes da semeadura do pepino, com irrigações diárias, com a finalidade de proliferar o patógeno nas unidades experimentais.

Utilizaram-se sementes de pepino 'Wisconsin SMR 18' com 97\% de poder de germinação, sem tratamento químico comercial, sendo previamente desinfestadas por cinco minutos em água destilada com hipoclorito de sódio a 5\%. Após a desinfestação, as sementes foram lavadas em água destilada e colocadas em papel absorvente para secagem, sendo em seguidas tratadas com $10 \mathrm{~mL}$ de cada tratamento para 100 sementes.

A semeadura foi feita colocando-se uma semente por célula, logo após o tratamento com o óleo essencial. As bandejas foram colocadas na Câmara de Crescimento, à temperatura de $25{ }^{\circ} \mathrm{C} \pm 2{ }^{\circ} \mathrm{C}$ e $65 \% \pm 10 \%$ de umidade relativa, por oito dias. Foram realizadas duas avaliações, de acordo com as Regras para Análises de Sementes - RAS (BRASIL, 2009), sendo a primeira aos quatro dias e a segunda, aos oito dias após a implantação dos testes. As quatro dias, realizou-se a contagem de sementes emergidas, sendo os resultados expressos em porcentagem de emergência.

Na segunda avaliação, realizou-se a contagem de sementes emergidas e de plântulas com tombamento de pós-emergência (TPE). Em seguida, procedeu-se a mensuração do comprimento das plântulas em papel milimetrado e a pesagem em balança analítica para obter a massa fresca. Os resultados desta foram expressos em porcentagem de emergência, porcentagem de TPE, comprimento médio de plântulas e massa fresca média por plântula.

Ao final do experimento, separou-se material vegetal misto de raízes e parte aérea das plântulas de pepino, que foram armazenadas em freezer a $-20{ }^{\circ} \mathrm{C}$ até as avaliações bioquímicas. As avaliações bioquímicas realizadas foram as seguintes: teor de proteínas totais (BRADFORD, 1976); atividade enzimática de peroxidases (MATSUNO; URITANI, 1972); fenilalanina amônia-liase (FAL) (HYODO et al., 1978; RODRIGUES et al., 2006); $\beta$-1,3-glucanases e quitinases (GUZZO et al., 1996).

Os resultados obtidos foram submetidos à análise estatística por meio de teste de normalidade de Lilliefors, análise de variância e testes complementares (análise de

Cultura Agronômica, Ilha Solteira, v.25, n.4, p.373-386, 2016 
regressão), a 5\% de probabilidade. Dados que não atenderam os pressupostos do modelo matemático foram avaliados por desvio padrão da média.

\section{RESULTADOS E DISCUSSÃO}

O crescimento micelial de $S$. sclerotiorum foi afetado negativamente pelo uso de óleo essencial de $A$. citriodora no meio BDA, mesmo nas menores doses testadas (Figura 1). O potencial antifúngico do óleo essencial de A. citriodora observado neste trabalho em baixas concentrações, é relatado também por Lozada et al. (2012). Estes autores observaram que a utilização de óleo essencial desta espécie e de outras espécies de Aloysia, em teste in vitro, reduziram o crescimento do fungo Moniliophthora roreri, causador de moniliniose em cacau, na dose de $0,2 \%$ e causou inibição total do micélio do patógeno, nas concentrações de $0,8 \%$ a $1 \%$.

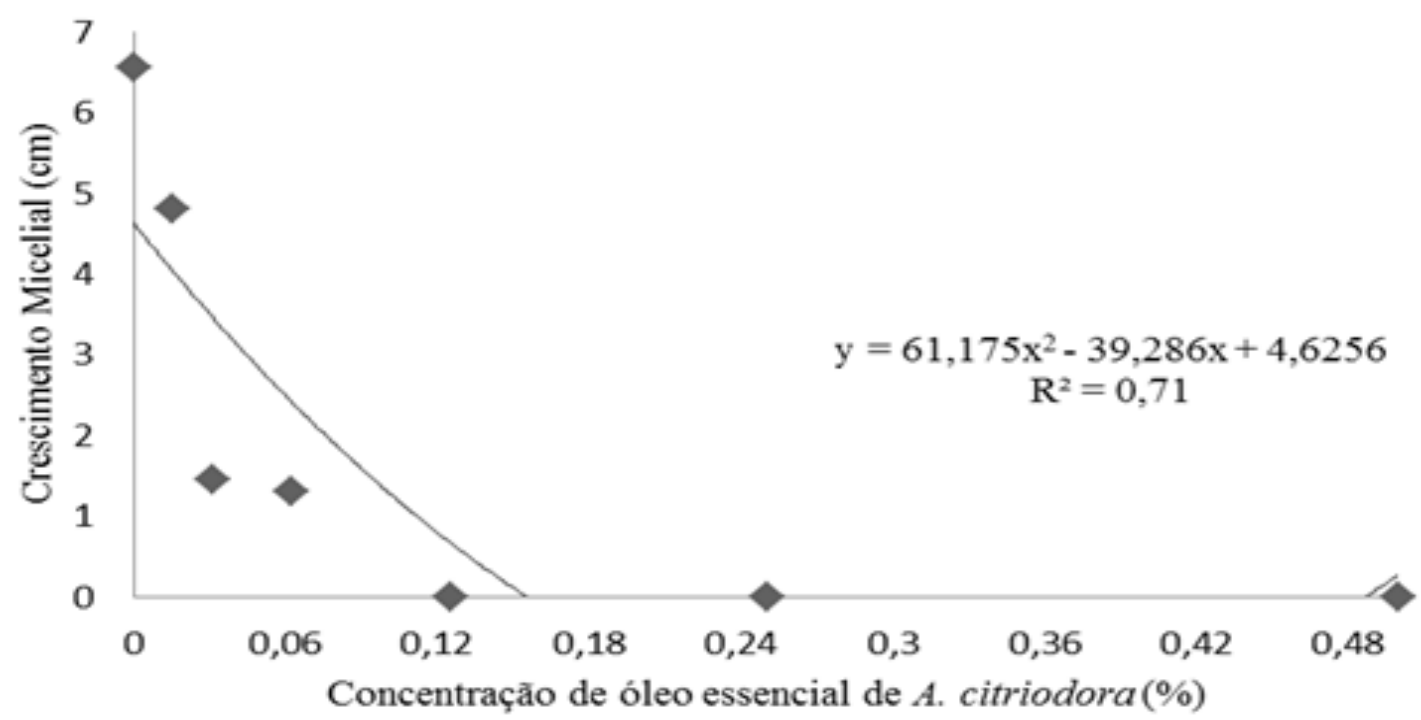

Figura 1. Crescimento micelial de S. sclerotiorum em função de concentrações de óleo essencial de A. citriodora em placas de Petri ${ }^{\circledR}$ contendo meio BDA, 72 horas após incubação em câmara de crescimento a $24{ }^{\circ} \mathrm{C} \pm 1{ }^{\circ} \mathrm{C}$ e fotoperíodo de 12 horas.

Combrinck et al. (2011), verificaram que a concentração mínima necessária de óleo essencial de A. citriodora para inibir $100 \%$ do crescimento micelial in vitro, dos patógenos Colletotrichum gloeosporioides do abacate e da manga, Alternaria citrii de laranjas e Botrytis cinerea de uvas foi de 0,2\%, e para Penicillium digitatum de laranjas e Lasiodioplodia theobramae de mangas foi de $0,3 \%$.

Bouchra et al. (2003), relataram que na concentração de 0,02\% em meio BDA, o óleo essencial desta planta reduziu o crescimento micelial in vitro, nas taxas de 69,4\% para $B$. cinerea, 68,2\% para Phytophthora citriophthora, 44,4\% para Penicillium digitatum e em 40,4\% para Geotrichum citri-aurantii. E significativa redução do crescimento micelial in vitro de Fusarium verticillioides foi observado por López et al. (2004), nas faixas de concentração em meio de cultura entre $0,02 \%$ a $0,05 \%$.

Cultura Agronômica, Ilha Solteira, v.25, n.4, p.373-386, 2016 
A germinação de escleródios de $S$. sclerotiorum também foi afetada in vitro pelas concentrações de óleo essencial de A. citriodora. Observou-se efeito linear decrescente com o aumento da concentração testada, chegando a ter uma total redução ou efeito $100 \%$ fungicida/fungistárico na concentração de $0,25 \%$, observado pelo cálculo do seu índice de velocidade de germinação (Figura 2).

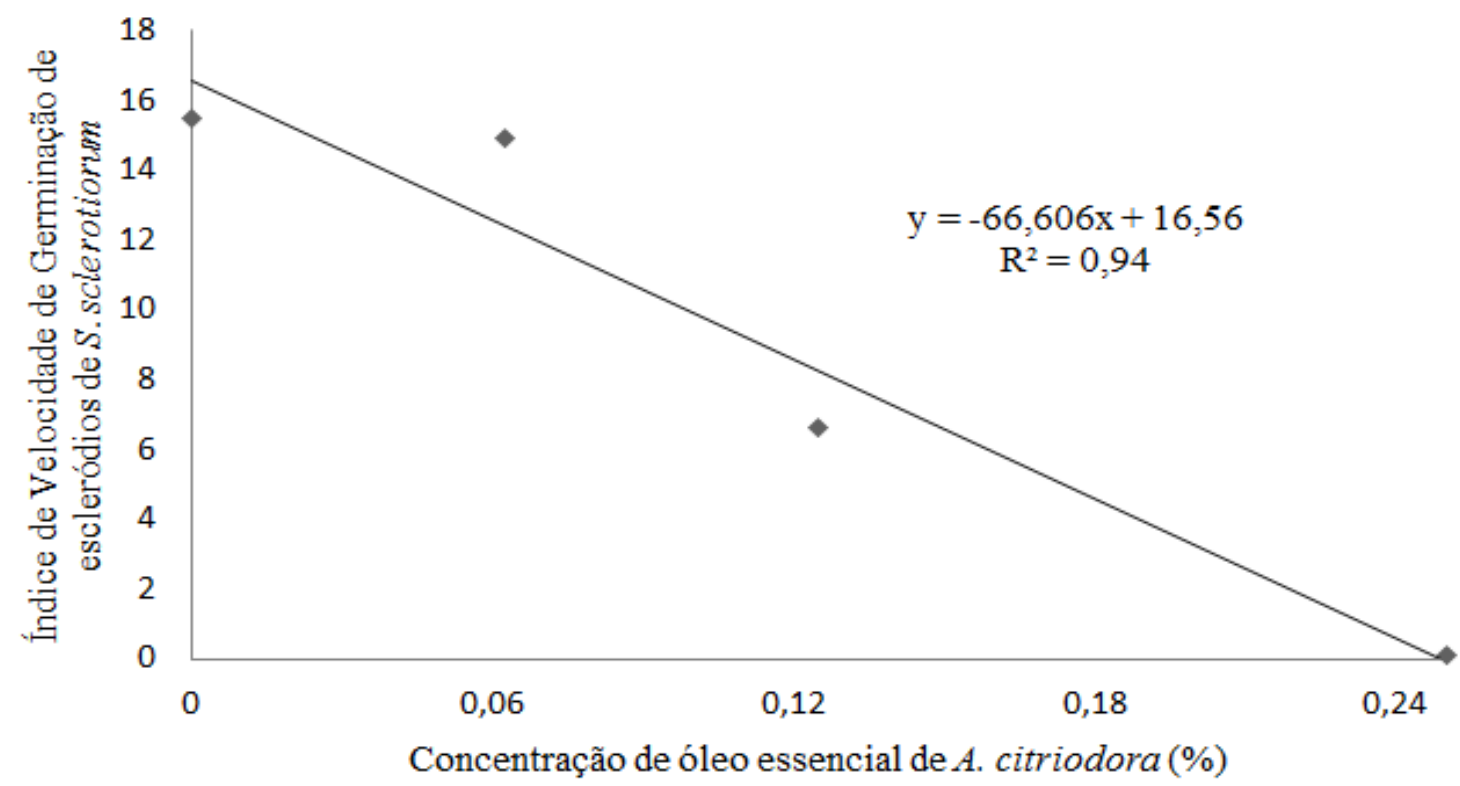

Figura 2. Índice de velocidade de germinação de escleródios de S. sclerotiorum, em função de concentrações de óleo essencial de A. citriodora em meio BDA, oito dias após incubação em câmara de crescimento a $24^{\circ} \mathrm{C} \pm 1{ }^{\circ} \mathrm{C}$, no escuro.

Paulus et al. (2013), estudando a composição química do óleo essencial de $A$. citriodora, para as mesmas condições de local, solo, estádio vegetativo, mês do ano, horário de coleta e método de extração, encontraram como principais componentes, o limoneno $(14,10 \%)$ e o citral (geranial + neral) $(49,69 \%)$.

O limoneno presente em óleos essenciais das plantas Mentha spicata e Anethum sowa, também é relatado com efeito antifúngico a vários patógenos humanos (AGGARVAL et al., 2002).

Extraído de citronela (Cymbopogon citratus), o citral é relatado com potencial de controle a várias espécies de fungos, como Candida albicans, Alternaria citrii, Aspergillus fumigatus, Aspergillus oryzae, Fusarium oxysporum, Fusarium solani, Helminthosporium compactum, Sclerotium rolfsii, Trichophyton mentagrophytes (PATTNAIK et al., 1997) e Rhizoctonia solani (GONÇALVES, 2012). Oriundo de Lippia alba, este composto teve atividade antifúngica a A. fumigatus e Candida krusei (MESA-ARANGO et al., 2009).

Em substrato contaminado com micélio de S. sclerotiorum, a porcentagem de emergência de plântulas de pepino aos quatro e nove dias, não foram influenciadas significativamente pelo tratamento das sementes com concentrações de óleo essencial de $A$. citriodora (Figura 3). Os tombamentos de pré-emergência não ocorreram muito provavelmente pelo fato do patógeno não ter atuado nesta fase de desenvolvimento das 
plântulas, pois o lote de sementes testado, possuía poder germinativo de $97 \%$, que foi o valor mínimo de emergência obtido no presente experimento.

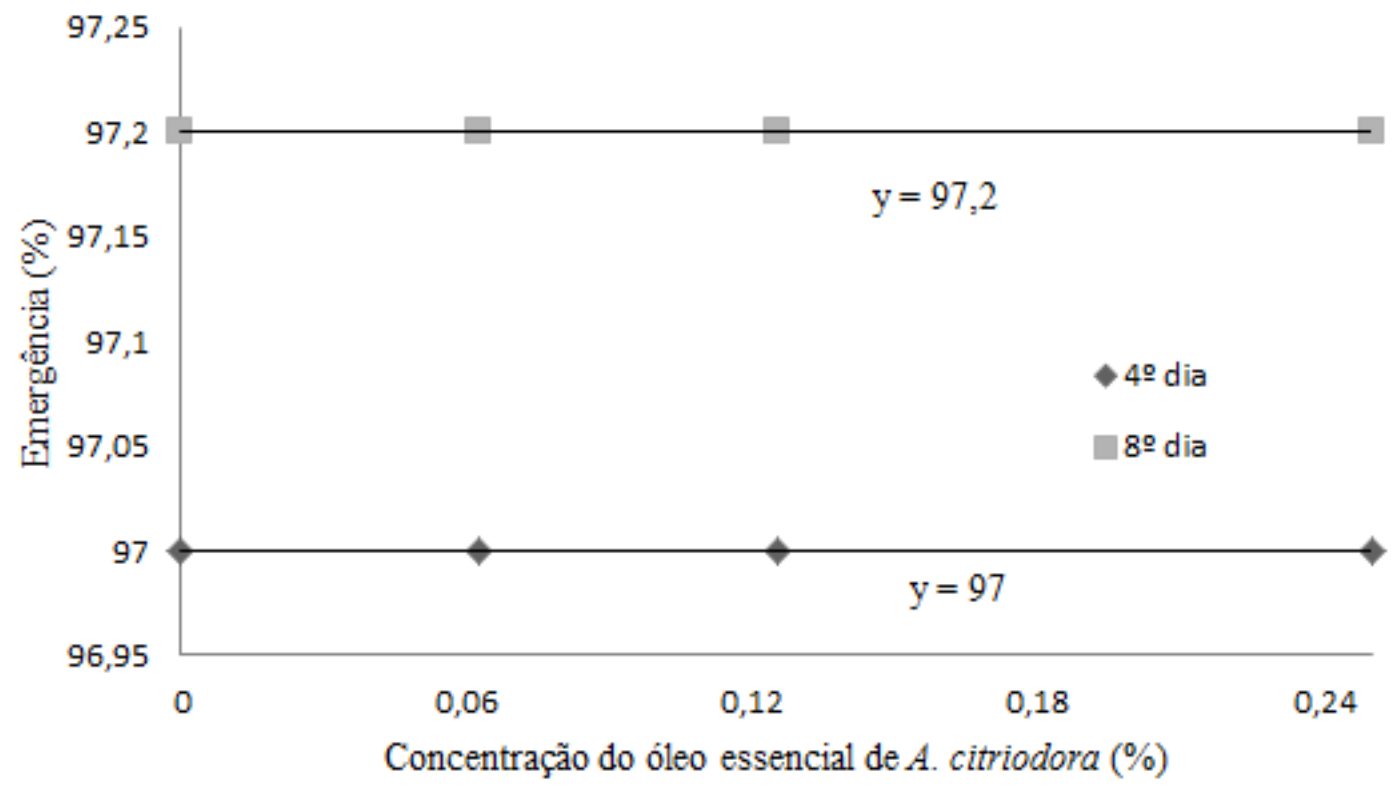

Figura 3. Porcentagem de emergência aos quatro e oito dias de plântulas de pepino cv. Wisconsin SMR 18, em substrato inoculado com S. sclerotiorum, com as sementes tratadas com concentrações de óleo essencial de $A$. citriodora, incubadas em câmara de germinação a $25^{\circ} \mathrm{C} \pm 1^{\circ} \mathrm{C}$ e umidade relativa de $65 \% \pm 10 \%$, fotoperíodo de 12 horas, por oito dias.

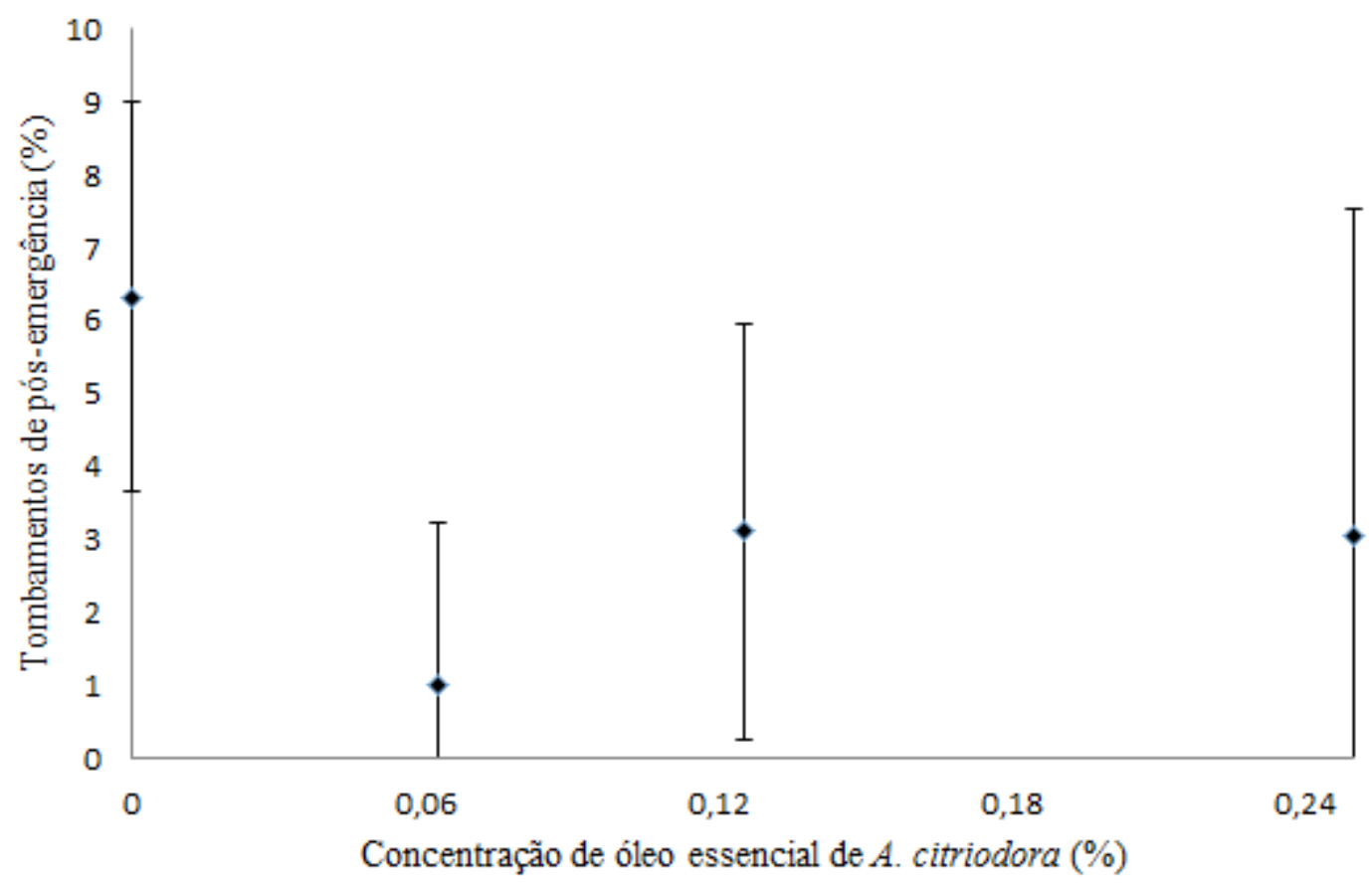

Figura 4. Tombamentos pós-emergência (TPE) aos oito dias de plântulas de pepino cv. Wisconsin SMR 18, em substrato inoculado com S. sclerotiorum, com as sementes tratadas com concentrações de óleo essencial de A. citriodora, incubadas em câmara de germinação a $25^{\circ} \mathrm{C} \pm 1^{\circ} \mathrm{C}$ e umidade relativa de $65 \% \pm 10 \%$, fotoperíodo de 12 horas, por oito dias.

Cultura Agronômica, Ilha Solteira, v.25, n.4, p.373-386, 2016 
Com relação ao tombamento de plântulas de pepino em pós-emergência (TPE), estes foram observados no experimento até oito dias após a semeadura. $\mathrm{O}$ uso do óleo essencial de $A$. citriodora diminuiu a ocorrência dos TPE com relação à testemunha do experimento, sendo que somente no tratamento das sementes com $0,06 \%$ esta variável foi estatisticamente significativa (Figura 4).

Nas variáveis massa verde e comprimento de plântulas, não houve influência significativa pelo tratamento das sementes com o óleo essencial (Figura 5). Ou seja, o uso do produto não foi favorável para o desenvolvimento das plântulas de pepino no presente trabalho e também não inibiu o seu crescimento, o que pode ser considerado positivo. Óleos essenciais têm sido relatados com efeitos alelopáticos a plantas quando aplicados às sementes, como por exemplo, no trabalho de Rosado et al. (2009), onde os autores observaram que o óleo essencial de manjericão (Oncimum basilicum L.) inibiu o índice de velocidade de germinação, comprimento de raízes e a porcentagem de germinação de alface, tomate e melissa.
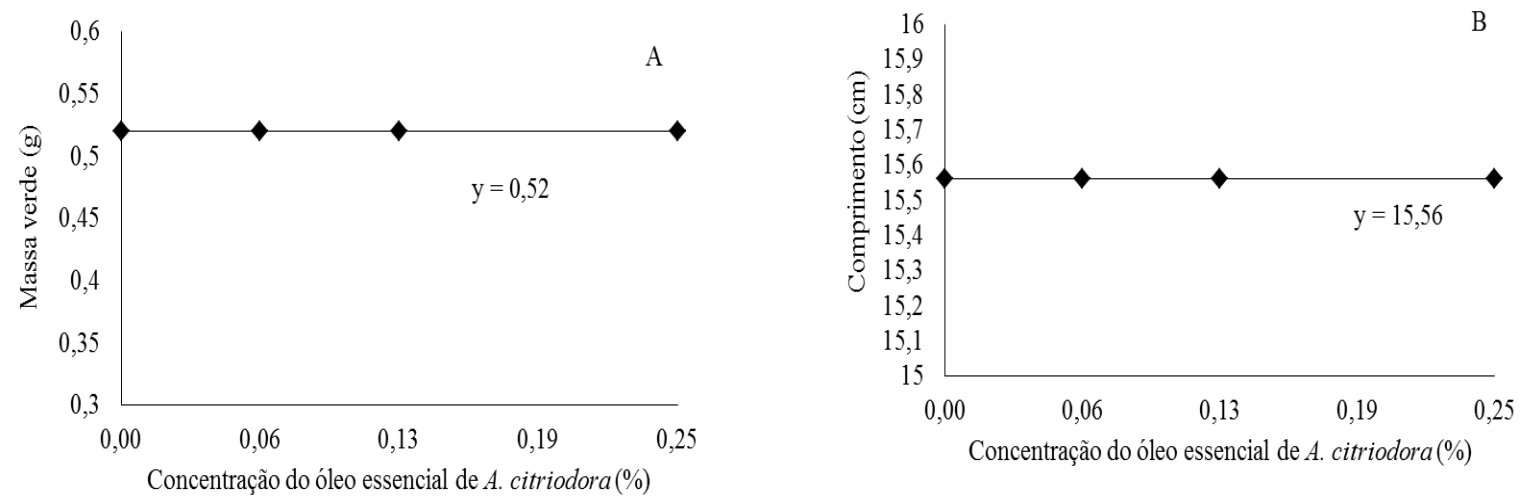

Figura 5. Massa verde média por plântula (A) e comprimento médio de plântulas (B) de pepino cv. Wisconsin SMR 18, em substrato inoculado com S. sclerotiorum, com as sementes tratadas com concentrações de óleo essencial de A. citriodora, incubadas em câmara de germinação a $25^{\circ} \mathrm{C} \pm 1^{\circ} \mathrm{C}$ e umidade relativa de $65 \% \pm 10 \%$, fotoperíodo de 12 horas, por oito dias.

Com relação às análises bioquímicas realizadas nos tecidos vegetais das plântulas de pepino, observou-se que o teor de proteínas foi influenciado pelas concentrações de óleo essencial de $A$. citriodora testadas no tratamento das sementes (Figura 6A). Não houve diferenciação dos tratamentos com a testemunha, no entanto, o tratamento das sementes com $0,06 \%$ de óleo essencial foi estatisticamente superior ao tratamento de maior dose $(0,25 \%)$ (Figura 6A). Este resultado pode estar relacionado com os resultados obtidos com os TPE, onde houve menor valor desta variável no tratamento das sementes com $0,06 \%$ de óleo essencial de A. citriodora (Figura 4), ou seja, quanto maior o teor de proteínas dos tecidos das plântulas de pepino, menor número de TPE ocorreram.

Mesmo não havendo uma proteção efetiva das plantas contra o damping off, a atividade de peroxidases foi influenciada pelo tratamento das sementes com óleo essencial de $A$. citriodora, todas as concentrações tiveram resultado superior ao encontrado na 
testemunha (Figura 6B), o que é de suma importância na defesa das plântulas ao tombamento causado por patógenos. A ativação de peroxidases em pepino, eliciada por extratos brutos aquosos e óleos essenciais extraídos de plantas, é relatada por Franzener et al. (2011).
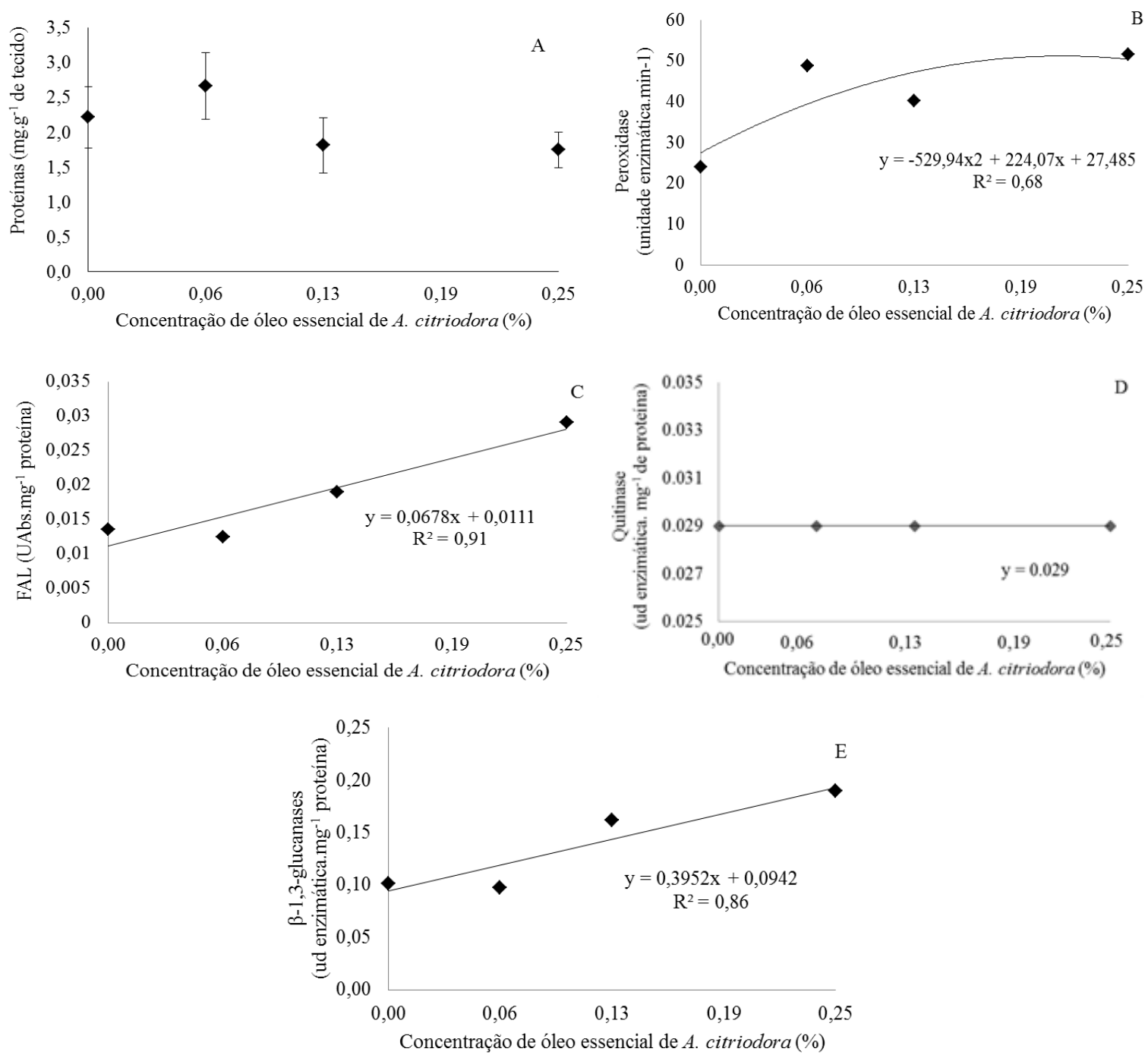

Figura 6. Atividade bioquímica dos tecidos vegetais (folhas e raízes) de plântulas de pepino cv. Wisconsin SMR 18, em substrato inoculado com $S$. sclerotiorum, com as sementes tratadas com concentrações de óleo essencial de A. citriodora, incubadas em câmara de germinação a $25^{\circ} \mathrm{C} \pm 1^{\circ} \mathrm{C}$ e umidade relativa de $65 \% \pm 10 \%$, fotoperíodo de 12 horas, por oito dias. A: teor de proteínas; B: atividade enzimática de peroxidases; C: FAL; D: quitinases; E: $\beta$-1,3-glucanases.

A formação de espécies ativas de oxigênio, também chamada de explosão oxidativa, é uma das respostas mais rápidas de defesa vegetal após o reconhecimento do patógeno, atuando no reforço da parede celular, pela ligação cruzada de proteínas estruturais ou de componentes fenólicos, formando uma barreira mecânica efetiva e de forma direta como agente antimicrobiano (RESENDE et al., 2003). Além de participar ativamente no controle

Cultura Agronômica, Ilha Solteira, v.25, n.4, p.373-386, 2016 
de fitopatógenos, as peroxidases de acordo com Pinto et al. (2011), podem atuar em vias de sinalização de rotas de defesa vegetal.

A atividade bioquímica da enzima fenilalanina amônia-liase (FAL) foi influenciada significativamente pelo tratamento das sementes com óleo essencial de A. citriodora de forma linear crescente com o aumento da concentração (Figura 6C). Stangarlin et al. (2011) relatam que a FAL, juntamente com a peroxidase, são consideradas enzimas chave de defesa vegetal, entre o metabolismo primário e o secundário, sendo que a primeira é importante na formação dos compostos fenólicos. Como exemplo de compostos fenólicos que tem como precursor a FAL, tem-se as cumarinas, ligninas, taninos, flavonoides e isoflavonóides (GARCIA; CARRIL, 2009).

Para o controle de tombamentos de plântulas, a formação de lignina é de suma importância, pois a mesma está relacionada com a maturação dos tecidos do vegetal. De acordo com Bedendo (2011), uma das medidas de controle desse tipo de doença, é a promoção do rápido desenvolvimento da plântula, com maturação dos tecidos jovens, que passam dessa forma a serem resistentes.

A atividade enzimática de quitinases nos tecidos vegetais das plântulas de pepino, não foi influenciada de forma significativa pelo tratamento das sementes com óleo essencial de A. citriodora, pois com o uso do mesmo, não houve diferença estatística quando comparado à testemunha (Figura 6D). Ao contrário, algumas pesquisas demonstram que óleos essenciais têm induzido o aumento da atividade enzimática de quitinases, como exemplo tem-se a videira, pela aplicação do óleo essencial de alecrim (Rosmarinus officinalis) (MAIA et al., 2014).

Já a atividade enzimática de $\beta$-1,3-glucanases foi influenciada pelo tratamento das sementes com A. citriodora, sendo que, assim como no resultado obtido para FAL, observou-se aumento linear crescente desta variável, com o aumento da concentração do produto utilizado (Figura 6E).

De acordo com Massola Júnior e Krugner (2011), S. sclerotiorum, é um fungo verdadeiro e assim como os quais, possuem em suas paredes celulares, $\beta$-glucanas e quitina. As $\beta$-1,3-glucanases são enzimas líticas, que possuem potencial para hidrolisar as $\beta$ glucanas presentes na parede celular de fungos, classificadas como "Proteínas Relacionadas à Patogênese" (Proteínas-RP) (PASCHOLATI, 2011). Pesquisas têm relacionado o uso de indutores de enzimas líticas como a glucanase, em tecidos vegetais, no controle de $S$. sclerotiorum, como por exemplo em canola (FERNANDO et al., 2007) e em alcachofra (MARCUCCI et al., 2010).

\section{CONCLUSÃO}

O uso do óleo essencial no tratamento de sementes de pepino, na concentração de $0,06 \%$, colaborou na redução da incidência de tombamentos de pós-emergência em substrato inoculado com S. sclerotiorum. Este resultado pode estar atribuído à atividade fungistatica ou fungicida direta, observados no teste in vitro realizados no primeiro trabalho. 
A redução dos tombamentos pode também estar atrelada aos mecanismos de defesa ativados nas plântulas de pepino. Os mecanismos de defesa vegetal ativados no presente trabalho estão relacionados com o aumento da atividade bioquímica das enzimas peroxidases, FAL e $\beta$-1,3-glucanases.

\section{REFERÊNCIAS BIBLIOGRÁFICAS}

AGGARVAL, K. K.; KHANUJA, S. P. S.; AHMAD, A.; SANTHA KUMAR, T. R.; GUPTA, V. K.; KUMAR, S. Antimicrobial activity profiles of the two enantiomers of limonene and carvone isolated from the oils of Mentha spicata and Anethum sowa. Flavour and Fragance Journal, Chichester, v. 17, n. 1, p.59-63, 2002.

ALI, H. F. M.; EL-BELTAGI, H. S.; NASR, N. F. Evaluation of antioxidant and antimicrobial activity of Aloysia triphylla. Electronic Journal of Environmental, Agricultural and Food Chemistry, Grand Forks, v. 10, n. 11, p.3044-3053, 2011.

BEDENDO, I. P. Damping-off. In: AMORIM, L.; REZENDE, J. A. M.; BERGAMIN FILHO, A. Manual de Fitopatologia 1: Princípios e Conceitos. São Paulo: Agronômica Ceres, 2011. cap. 22, p. 435-441.

BRADFORD, M. M. A rapid and sensitive method for the quantification of microgram quantities of protein utilizing the principle of protein-dye binding. Analytical Biochemistry, New York, v. 72, n. 1-2, p.248-254, 1976.

BRASIL. Ministério da Agricultura, Pecuária e Abastecimento. Secretaria de Defesa Agropecuária. Regras para análises de sementes. Brasília: MAPA/ACS, 2009. 399 p.

BOUCHRA, C.; MOHAMED, A.; MINA, I. H.; HMAMOUCHI, M. Antifungal activity of essential oils from several medicinal plants against four postharvest citrus pathogens. Phytopathologia Mediterranea, Firenze, v. 42, n. 3, p.251-256, 2003.

COMBRINCK, S.; REGNIER, T.; KAMATOU, G. P. P. In vitro activity of eighteen essential oils and some major components against common postharvest fungal pathogens of fruit. Industrial Crops and Products, Amsterdam, v. 33, n. 2, p.344-349, 2011.

DUARTE, M. C. T.; FIGUEIRA, G. M.; SARTORATTO, A.; REHDER, V. L. G.; DELARMELINA, C.. Anti-Candida activity of Brazilian medicinal plants. Journal of Ethnopharmacology, Lausanne, v. 97, n. 2, p.305-311, 2005.

ETHUR, L. Z.; BLUME, E.; MUNIZ, M.; SILVA, A. C. F.; STEFANELO, D. R.; ROCHA, E. K. Fungos antagonistas a Sclerotinia sclerotiorum em pepineiro cultivado em estufa. Fitopatologia Brasileira, Brasília, v. 30, n. 2, p.127-133, 2005.

FERNANDO, W. G. D.; NAKEERAN, S.; ZHANG, Y.; SAVCHUK, S. Biological control of Sclerotinia sclerotiorum (Lib.) de Bary by Pseudomonas and Bacillus species on canola petals. Crop Protection, Guildford, v. 26, n. 2, p.100-107, 2007.

FRANZENER, G.; MOURA, G. S.; MEINERZ, C. C.; SCHWAN-ESTRADA, K. R. F.; STANGARLIN, J. R. Extrato aquoso de Corymbia citriodora no controle alternativo da 
antracnose em pepino e do crestamento bacteriano em feijão. Cadernos de Agroecologia, Recife, v. 6, n. 2, p.1-5, 2011.

GARCIA, A. Á.; CARRIL, E. P. U. Metabolismo secundário de plantas. Reduca (Biologia), Madrid, v. 2, n. 3, p.119-145, 2009.

GONÇALVES, A. H. Atividade fungitóxica dos óleos essenciais de Lippia sidoides Cham. e de Cymbopogon citratus (D.C.) Stapf. no controle de fitopatógenos do feijoeiro comum. 2012. 90 f. Dissertação (Mestrado em Produção Vegetal), Universidade Federal do Tocantins, Gurupi, 2012.

GUZZO, S. D.; MARTINS, E. M. F. Local and systemic induction of $\beta$-1,3-glucanase and chitinase in coffee leaves protected against Hemileia vastatrix by Bacillus thuringiensis. Journal of Phytopathology, Berlin, v. 144, n. 9-10, p.449-454, 1996.

HYODO, H.; KURODA, H.; YANG, S. F. Induction of phenylalanine ammonia-lyase and increase in phenolics in lettuce leaves in relation to the development of russet spotting caused by ethylene. Plant Physiology, Minneapolis, v. 62, n. 1, p.31-35, 1978.

LÓPEZ, A. G.; THEUMER, M. G.; ZYGADLO, J. A.; RUBINSTEIN, H. R. Aromatic plants essential oils activity on Fusarium verticillioides Fumonisin $\mathrm{B}_{1}$ production in corn grain. Mycopathologia, Den Haag, v. 158, n. 3, p.343-349, 2004.

LOZADA, B. S.; HERRERA, L. V.; PEREA, J. A.; STASHENKO, E.; ESCOBAR, P. In vitro effect of essential oils of three Lippia species on Moniliophthora roreri (Cif. and Par.) Evans et al., causative agent of moniliasis of cocoa (Theobroma cacao L.). Acta Agronomica, Bogotá, v. 61, n. 2, p.94-102, 2012.

MAIA, A. J.; SCHWAN-ESTRADA, K. R. F.; FARIA, C. M. D. R.; OLIVEIRA, J. S. B.; JARDINETTI, V. A.; BATISTA, B. N. Óleo essencial de alecrim no controle de doenças e na indução de resistência em videira. Pesquisa Agropecuária Brasileira, Brasília, v. 49, n. 5, p.330-339, 2014.

MARCUCCI, E.; ALEANDRI, M. P.; CHILOSI, G.; MAGRO, P. Induced resistance by $\beta$ Aminobutiric aci in artichoke against white mould caused by Sclerotinia sclerotiorum. Journal of Phytopathology, Berlin, v. 158, n. 10, p.659-667, 2010.

MASSOLA JÚNIOR, N. S.; KRUGNER, T. L. Fungos fitopatogênicos. In: AMORIM, L.; REZENDE, J. A. M.; BERGAMIN FILHO, A. Manual de Fitopatologia 1: Princípios e Conceitos. São Paulo: Agronômica Ceres, 2011. cap. 35, p. 149-206.

MATSUNO, H.; URITANI, I. Physiological behavior of peroxidase isozymes in sweet potato root tissui injured by cutting or with black rot. Plant \& Cell Physiology, Tokyo, v. 13, n. 6, p.1091-1101, 1972.

MESA-ARANGO, A. C.; MONTIEL-RAMOS, J.; ZAPATA, B.; DURÁN, C.; BETANCUR-GALVIS, L.; STASHENKO, E. Citral and carvone chemotypes from the essential oils of Colombian Lippia alba (Mill.) N. E. Brown: composition, citotoxity and antifungal activity. Memórias do Instituto Oswaldo Cruz, Rio de Janeiro, v. 104, n. 6, p.878-884, 2009.

Cultura Agronômica, Ilha Solteira, v.25, n.4, p.373-386, 2016 
MORAIS, L. A. S. Óleos essenciais no controle fitossanitário. In: BETTIOL, W.; MORANDI, M.A.B. Biocontrole de doenças de plantas: uso e perspectivas. Jaguariúna: Embrapa Meio Ambiente, 2009. cap. 9, p. 139-152.

PASCHOLATI, S. F. Fisiologia do parasitismo: como as plantas se defendem dos patógenos. In: AMORIM, L.; REZENDE, J. A. M.; BERGAMIN FILHO, A. Manual de Fitopatologia 1: Princípios e Conceitos. São Paulo: Agronômica Ceres, 2011. cap. 35, p. 593-636.

PATTNAIK, S.; SUBRAMANYAM, V. R.; BAPAJI, M.; KOLE, C. R. Antibacterial and antifungal activity of aromatic constituintes of essential oils. Microbios, Cambridge, v. 89, n. 358, p.39-46,1997.

PAULUS, D.; VALMORBIDA, R.; TOFFOLI, E.; NAVA, G. A.; PAULUS, E. Teor e composição química do óleo essencial e crescimento vegetativo de Aloysia triphylla em diferentes espaçamentos e épocas de colheita. Revista Ceres, Viçosa, v. 60, n. 3, p.372-379, 2013.

PINTO, M. S. T.; RIBEIRO, J. M.; OLIVEIRA, E. A. G. O estudo de genes e proteínas de defesa em plantas. Revista Brasileira de Biociências, Porto Alegre, v. 9, n. 2, p.241-248, 2011.

RESENDE, M. L. V.; SALGADO, S. M L.; CHAVES, Z. M. Espécies ativas de oxigênio na resposta de defesa de plantas a patógenos. Fitopatologia Brasileira, Brasília, v. 28, n. 2, p.123-130, 2003.

RODRIGUES, A. A. C.; BEZERRA NETO, E.; COELHO, R. S. B. Indução de resistência a Fuzarium oxysporum $f$. sp. tracheiphilum em caupi: eficiência de indutores: abióticos e atividade enzimática elicitada. Fitopatologia Brasileira, Brasília, v. 31, n. 5, p.492-499, 2006.

ROSADO, L. D. S.; RODRIGUES, H. C. A.; PINTO, J. E. B. P.; CUSTÓDIO, T. N.; PINTO, L. B. B.; BERTOLUCCI, S. K. V. Alelopatia do extrato aquoso e do óleo essencial de folhas do manjericão "Maria Bonita" na germinação de alface, tomate e melissa. Revista Brasileira de Plantas Medicinais, Paulínia, v. 11, n. 4, p.422-428, 2009.

SCHWAN-ESTRADA, K. R. F. Extratos vegetais e de cogumelos no controle de doenças de plantas. Horticultura Brasileira, Vitória da Conquista, v. 27, n. 2, p.4038-4045, 2009.

SCHWAN-ESTRADA, K. R. F; STANGARLIN, J. R.; CRUZ, M. E. S. Uso de extratos vegetais no controle de fungos fitopatogênicos. Revista Floresta, Curitiba, v. 30, n. 1/2, p.129-137, 2000.

SMITH, C. J. Accumulation of phytoalexins: defense mechanisms and stimulus response system. The New Phytologist, Oxford, v. 132, n. 1, p.1-45, 1996.

STANGARLIN, J. R.; KUHN, O. J.; TOLEDO, M. V.; PORTZ, R. L.; SCHWANESTRADA, K. R. F.; PASCHOLATI, S. F. A defesa vegetal contra fitopatógenos. Scientia Agraria Paranaensis, Marechal Cândido Rondon, v. 10, n. 1, p.18-46, 2011.

Cultura Agronômica, Ilha Solteira, v.25, n.4, p.373-386, 2016 
VIDA, J. B.; ZAMBOLIM, L.; TESSMANN, D. J.; BRANDÃO FILHO, J. USAN T.; VERZIGNASSI, J. R.; CAIXETA, M. P. Manejo de doenças de plantas em cultivo protegido. Fitopatologia Brasileira, Brasília, v. 29, n. 4, p.355-372, 2004. 